\title{
Evaluation of two rapid immunochromatographic tests for diagnosis of brucellosis infection in cattle
}

\author{
Anitza Fragas Quintero ${ }^{1, *}$, Dervel Felipe Díaz Herrera ${ }^{2}$, Dayamí Martín Alfonso ${ }^{1}$, Yanelis Cruz Santana ${ }^{1}$, \\ Raisa Betancourt Torres ${ }^{1}$ and Lucy Montano Tamayo ${ }^{1}$

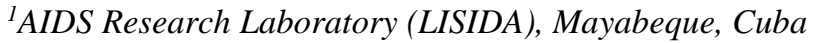 \\ ${ }^{2}$ National Center for Animal and Plant Health (CENSA), Mayabeque, Cuba
}

\begin{abstract}
Brucellosis is a serious infectious disease that causes significant economic losses in the livestock industry. Its early diagnosis allows an adequate disease control in cattle. DAVIH Laboratories designed a lateral flow immunochromatographic assay using protein A-colloidal gold as a detector reagent (LFIA-PA). The objective of this work was to compare the performance of this assay using protein G-colloidal gold (LFIA-PG) with its performance using protein A-colloidal gold as the detector reagent. The assays were carried out with $20 \mu \mathrm{L}$ of serum and $130 \mu \mathrm{L}$ of running buffer. Interpretation of bands was by visual inspection with the naked eye at 15-20 minutes after sample application. The tests were evaluated with 449 samples of bovine serum (111 positive and 338 negative). The diagnostic sensitivity and specificity, the positive and negative predictive values, and the efficacy of both assays were calculated, and their concordance was estimated by calculating the kappa $(\mathrm{k})$ index. The estimated values of the parameters for LFIA-PG and LFPIA-PA were $100 \%$ and $95.2 \%$ of diagnostic sensitivity, 96.2\% and $97.3 \%$ of diagnostic specificity, $89.5 \%$ and $92.3 \%$ for the positive predictive value, $100 \%$ and $98.5 \%$ for the negative predictive value, and $97.1 \%$ and $96.89 \%$ of efficacy, respectively. The concordance between both tests was very good $(k=0.95)$. It was shown the possibilities of developing a system with LFIA-PG capable of detecting antibodies against Brucella spp. The performance of the test makes possible its use as a screening method in the diagnosis of brucellosis.
\end{abstract}

Keywords: Bovine, Brucella spp., Brucellosis, Diagnosis, Rapid immunochromatographic test.

\section{Introduction}

Bovine brucellosis is caused mainly by Brucella abortus (Sbriglio et al., 2007; Dongre and Maheshwari, 2013). This microorganism shows affinity for the reproductive tract; it is mainly characterized by the production of abortions, altering the reproduction. This infection has a worldwide distribution. Especially in dairy cattle, it has a great economic and social importance because of the huge losses it can cause in the livestock industry, the potential barriers it creates to the international trade of animals and animal products, and the occupational risk that it represents for the farmers, veterinarians, and butchers who handle either animals or animal consumption of contaminated products (Gasque, 2008; Moreno, 2014; Bamaiyi, 2016).

In cattle, the disease is transmitted through grazing in contaminated areas, consumption of water contaminated with secretions, as well as through infected fetal membranes and contact with aborted fetuses or infected neonates.

In humans, the disease is transmitted by ingestion, penetration through the conjunctiva, through the skin or by the udder contamination during milking. In addition, the infection also occurs through the consumption of raw products from infected animals (Gasque, 2008). This duality, where the infection can be perpetuated in both animals and humans, makes brucellosis to be observed with a new approach: "one health" (Sbriglio et al., 2007; Gasque, 2008; Moreno, 2014).

In Cuba and worldwide, cattle is one of the most economically important species, hence the need to carry out a strict control of brucellosis in livestock (Sbriglio et al., 2007; Gasque, 2008; Dongre and Maheshwari, 2013).

According to the World Organization for Animal Health (OIE), the Rose Bengal test, the standard tube agglutination, the complement fixation method, the slow agglutination test with 2- Mercaptoethanol, the determination of immunoglobulins $\mathrm{G}$ (IgG), A (IgA) and $\mathrm{M}(\mathrm{IgM})$ by ELISA-type immunoenzymatic assays, and the Fluorescent Polarization assay are the serological techniques commonly used for brucellosis diagnosis (NRAG 586, 1982; Dongre and Maheshwari, 2013; Galińska and Zagórski, 2013; OIE, 2016).

At present, bacterial DNA testing is also used, but its diffusion and availability are still scarce because of its requirements of qualified personnel, specific laboratory equipment, cold chain, and electric fluid. Thus, it is not feasible for the surveillance and diagnosis of 
brucellosis, especially under field conditions, where large numbers of animals are examined (Galińska and Zagórski, 2013; Moreno, 2014; OIE, 2016).

In the last 10 years, rapid lateral flow immunochromatographic test formats have been designed and evaluated in the screening and surveillance of brucellosis, both in herds and in humans.

These tests present a similar performance to the ELISA systems (Beesley, 1989; Díaz et al., 2015; Geresu and Kassa, 2016), but their use does not require highly trained personnel, specific materials and equipment, or expensive reagents.

They are a novel alternative for low-income countries and hard-to-reach populations (Abdoel et al., 2008; OIE, 2016), where an effective diagnosis of this infection at the herd level and an adequate control of the disease in cattle can be attained (Díaz et al., 2015; Geresu and Kassa, 2016; OIE, 2016).

DAVIH Laboratories (Mayabeque, Cuba) developed a lateral flow immunochromatographic assay with a colloidal protein A-gold conjugate (LFIA-PA) (Díaz et al., 2015). The evaluation of the assay with this detector reagent showed an adequate performance. However, high levels of sensitivity reached by this type of assay were reported when protein G-colloidal gold were used as the detector reagent, attributed to its high affinity for bovine $\operatorname{IgG}$ immunoglobulins (Hermanson, 1996; Geresu and Kassa, 2016). The objective of this work was to compare the performance of a lateral flow immunochromatographic assay using protein Gcolloidal gold as a detector reagent with its performance using protein A-colloidal gold.

\section{Materials and Methods}

\section{Animals}

A total number of 449 bovine sera (111 positive and 338 negative) selected from the reference panel of DAVIH Laboratories (Mayabeque, Cuba) were used for the test evaluation. The samples included in the study were taken from different herds in both brucellosis-free and brucellosis-affected areas in Cuba. The samples were from the provinces Camaguiey (61 positive and 69 negative), Pinar del Río (50 positive and 155 negative), and Mayabeque (114 negative). They were characterized by conventional serological tests (Rose Bengal, Standard Agglutination Test, Complement Fixation and 2-Mercaptoethanol Test) (NRAG 586, 1982; Galińska and Zagórski, 2013; OIE, 2016).

The biological reagents necessary for the development of these techniques were produced in Cuba by the Biological Pharmaceutical Laboratories (LABIOFAM), and the methodology and interpretation criteria used for the evaluation of the results were those included in the Resolution 586 of the Institute of Veterinary Medicine of the Republic of Cuba: 1982,
Veterinary Diagnosis, Brucellosis, Test methods (NRAG 586, 1982).

The Rose Bengal test was performed as follows: $30 \mu \mathrm{l}$ of test serum was added to $30 \mu 1$ of commercial Rose Bengal antigen on a white porcelain plate and mixed thoroughly with a clean toothpick to produce an area of approximately $2 \mathrm{~cm}$ in diameter. The plate was shaken slowly for $3 \mathrm{~min}$. The test was read and scored as positive if any degree of agglutination was observed (NRAG 586, 1982; OIE, 2016).

The Standard Agglutination Test was performed with a Brucella abortus strain 99 antigen, diluted to 5\% in $0.85 \%$ saline solution, with $0.5 \%$ phenol. Four glass tubes were used per sample, each tube containing 0.08 $\mathrm{mL}, 0.04 \mathrm{~mL}, 0.02 \mathrm{~mL}$ and $0.01 \mathrm{~mL}$ of serum. Two $\mathrm{mL}$ of the diluted antigen was added to each tube. The samples were incubated at $37^{\circ} \mathrm{C}$ for $16-24$ hours. Those samples with a film at the bottom of the tube and a clear supernatant from the 1: 100 dilution were considered positive; those samples with no films and associated with cloudy supernatant were considered negative (NRAG 586, 1982; Galińska and Zagórski, 2013).

The Complement fixation test (CFT) was carried out in a microtitre format by hot fixation with two units of complement. Test sera and positive and negative controls were diluted two fold in Veronal Buffer (VB), starting from 1:5 dilutions. Diluted serum samples (1:5) were inactivated at $58^{\circ} \mathrm{C}$ for $50 \mathrm{~min}$. The minimum haemolytic dose (MHD) was estimated for each test set-up using 2\% sensitized sheep red blood cell (SRBC) in VB. Two MHD units were used throughout the test. The end point titre was taken as the first well showing approximately 50\% lysis of SRBC. Serum dilutions of 1:5 or higher giving a titre equivalent to 20 international CFT unit (ICFTU)/ml or more were considered as positive for the CFT (NRAG 586, 1982; OIE, 2016).

The 2-Mercaptoethanol (2-ME) test was performed with a Brucella abortus strain 99 antigen, diluted to $10 \%$ in saline buffer at $0.85 \%$. One $\mathrm{mL}$ of $0.1 \mathrm{M} 2-\mathrm{ME}$ solution was added to each of four glass tubes, each containing $0.08 \mathrm{~mL}, 0.04 \mathrm{~mL}, 0.02 \mathrm{~mL}$ and $0.01 \mathrm{~mL}$ of the sera to be analyzed. The tubes were incubated at $25^{\circ} \mathrm{C}$ for 1 hour, and then, $1 \mathrm{~mL}$ of the diluted antigen was added to each tube. Then, the tubes were incubated at $37{ }^{\circ} \mathrm{C}$ for $16-24$ hours. The reading of the reactions followed the same standard observed for the SAL, but, in this case, the samples were considered positive from the 1:25 dilution (NRAG 586, 1982; OIE, 2016).

\section{Sample collection}

An approximately $10 \mathrm{~mL}$ blood sample was collected from the jugular vein of each animal. The sera were obtained after blood centrifugation at $600 \mathrm{x}$ g for $5 \mathrm{~min}$. They were kept at $-20{ }^{\circ} \mathrm{C}$ and thawed at room temperature before being analyzed (Geresu and Kassa, 2016). 


\section{Assays}

The rapid immunochromatographic assay tested for bovine brucellosis diagnosis was the LFIA-PG manufactured according to the methodology developed by Díaz et al. (2015) (Fig. 1). The assay consists of a nitrocellulose $(15 \mu \mathrm{m})$ detection strip flanked at one end by a reagent pad and at the other end by an absorption pad. A sample application pad flanks the reagent pad in turn. The composite strip is contained in a plastic assay device. The detection strip contains Brucella lipopolysaccharide (LPS) and is applied by using a BioDotQuanti 2000 BioJet, England.

A mixture of human immunoglobulin $\mathrm{G}$ ( $\operatorname{IgG} \mathrm{h}$ ), purified by protein A-Sepharose affinity chromatography, and poly L-lysine (Sigma -Aldrich, SL, USA) was applied in a second line to function as a reagent control in the assay. The detector reagent (protein G-colloidal gold conjugate) was obtained by conjugating protein $\mathrm{G}$ (Sigma-Aldrich, SL, USA) to 40 $\mathrm{nm}$ diameter colloidal gold particles (British Biocell International, England), following the protocol described by Beesley (1989) and Hermanson (1996). The conjugate obtained was adjusted to an optical density of 0.220 , at a wavelength of $520 \mathrm{~nm}$, determined on a Genesys 10S UV-VIS spectrophotometer (Thermo Scientific, USA).

It was then diluted in a migration buffer and sprayed onto the conjugate pads with the air jet aerosol dispenser device of the BioDotQuanti 2000_BioJet equipment. The conjugate pads were dried at $37^{\circ} \mathrm{C}$ for 30 minutes. The amounts of conjugate applied to the test strips were optimized using positive and negative reference samples. The detection reagents were applied to the conjugate pad by using a BioDotQuanti 2000 BioJet, England apparatus. The strip tests were assembled by mounting the sample application pad, reagent pad, detection strip, and absorption pad onto a rigid support. The strips were placed in a plastic assay device with a round sample well positioned above the detection strip. Finally, they were sealed in moistureresistant foil envelopes containing silica gel bags.

The rapid immunochromatographic lateral flow test using protein G-colloidal gold (LFIA-PG), developed in this study, and the test developed by Díaz et al. (2015), using protein A-colloidal gold (LFIA-PA) as the detection reagent, were evaluated for detection of antibodies against Brucella spp. by the following process: Twenty $\mu$ l of serum were added on the sample pad, followed by $130 \mu \mathrm{L}$ of running buffer composed of saline solution - Phosphate $(\mathrm{pH} 7.6)$ with $1.67 \%$ albumin (Sigma-Aldrich, SL, USA) and 3\% Tween 20 (Merck, KGaA, Germany). Both tests were evaluated in parallel with each of the reference panel samples.

The interpretation of the results was by visual inspection with the naked eye at 15- 20 minutes after the samples were applied.

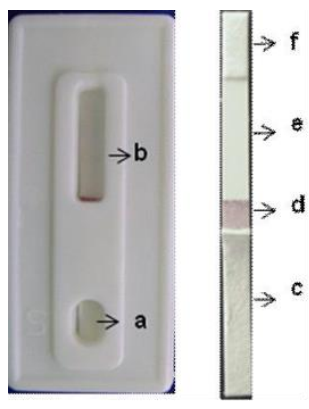

(A)

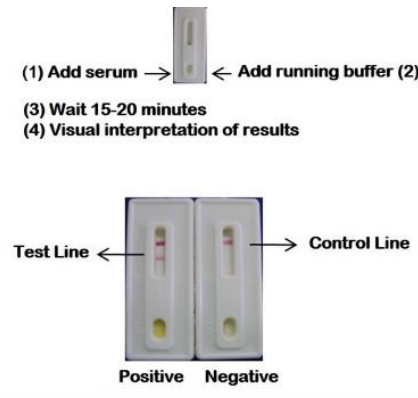

(B)
Fig. 1. Immunochromatographic lateral flow assay (ILFA) for brucellosis diagnosis: presentation, components and procedure. (A): Plastic assay device (left) containing a composite assay strip (right). (a): Sample application well; (b): Test and control window; (c): Sample application pad; (d): Conjugate pad; (e): Nitrocellulose membrane; (f): Absorption pad. (B): Procedure and result of the assay.

The test was considered valid when the control line appeared in all the cases. It was considered negative when only the control line appeared and positive when the two lines appeared.

\section{Analysis of Results}

The results obtained in each test were organized in contingency tables (Silva et al., 2006; Ochoa, 2013) for analysis. The diagnostic sensitivity and specificity, positive and negative predictive values, and efficacy of each test and the concordance between them were estimated. Contingency table 2 × 2 for the calculation of quality indicators:

\begin{tabular}{lccc}
\hline \multirow{2}{*}{$\begin{array}{l}\text { Test to } \\
\text { evaluate }\end{array}$} & Positive & Negative & Total \\
\cline { 2 - 4 } Positive & $\mathrm{a}$ & $\mathrm{b}$ & $\mathrm{a}+\mathrm{b}$ \\
Negative & $\mathrm{c}$ & $\mathrm{d}$ & $\mathrm{c}+\mathrm{d}$ \\
\hline Total & $\mathrm{a}+\mathrm{c}$ & $\mathrm{b}+\mathrm{d}$ & $\mathrm{n}$ \\
\hline
\end{tabular}

Sensitivity: a / $(a+c)$ x 100

a: True positive values

c: False negative values

Specificity: d $(b+d) \times 100$

b: False positive values

$\mathrm{d}$ : True negative values

$\mathrm{n}$ : Total samples in the study

Positive predictive value (PPV): $\mathrm{a} /(\mathrm{a}+\mathrm{b}) \mathrm{x} 100$

Negative predictive value (NPV): $d /(c+d) \times 100$

Efficiency: $[(\mathrm{a}+\mathrm{d}) / \mathrm{n}] \mathrm{x} 100$

For the Concordance study, the kappa index ( $k$ )was determined. It was based on the comparison of the expected concordance index (pe) with the observed concordance (po) indexes, and it was calculated as follows:

$\mathrm{k}=$ po-pe / 1-pe where:

po: $\mathrm{a}+\mathrm{d} / \mathrm{n}$

pe: $(\mathrm{P}+\mathrm{N}) / \mathrm{n}$

Concordance of the positive values $(\mathrm{P})$ :

$[(\mathrm{a}+\mathrm{b}) / \mathrm{n} \times(\mathrm{a}+\mathrm{c}) / \mathrm{n}] \mathrm{n}$

Concordance of negative values $(\mathrm{N})$ :

$(\mathrm{c}+\mathrm{d})-\{(\mathrm{a}+\mathrm{c})-\mathrm{P}\}$ 


\section{Results}

The evaluation of the immunochromatographic assays (LFIA-PG and LFIA-PA) with a panel of bovine reference samples from DAVIH Laboratories (Mayabeque, Cuba) are shown in Tables 1 and 2.

Table 3 shows the results of the performance parameters of the LFIA-PG and LFIA-PA systems with the bovine samples studied, and Table 4 shows the concordance results between them.

\section{Discussion}

Diagnostic systems are essential for control and monitoring of diseases. In the case of the veterinary profile, an easy access to the target livestock to be controlled is necessary to give an early analysis of the infection and take control and eradication measures, particularly when the disease is a reemerging zoonosis, such as in the case of brucellosis (Saegerman et al., 2004; Abdoel et al., 2008; Shome et al., 2015). At present, several institutions are working on the design of those immunoassays that offer greater advantages in the veterinary diagnosis. An example of this is the development and application of lateral flow immunochromatographic tests (Abdoel et al., 2008; Díaz et al., 2015; Shome et al., 2015).

There is not a serological test appropriated for all the epidemiological situations; therefore, all the factors influencing in the relevance of the analytical method and the test results for a particular diagnostic interpretation or application must be taken into account. In the case of the rapid lateral flow immunochromatographic tests, even when they are simple and fast running systems, reliable and accurate results are reported (Smits et al., 2003; Genç et al., 2012; Díaz et al., 2015), which, together with the possibility of carrying them to the fields where the herds are (as field tests), make them an alternative to the conventional serological diagnosis of brucellosis (Smits et al., 2003; Nielsen et al., 2004).

In the development of the LFIA-PG system, the appropriate concentration of the protein $G$ conjugate was obtained for printing on the pads, and the migration buffer and drying time at $37^{\circ} \mathrm{C}$ were effective. With the application of this conjugate, IgG antibodies were detected, since protein $\mathrm{G}$ had the ability to bind specifically and with high affinity to the Fc fragment of IgG (Saegerman et al., 2004; Díaz et al., 2015). Genç et al. (2012) also used a G-gold colloidal conjugate for diagnosis of brucellosis in cattle and sheep with reliable results. . In addition, Saegerman et al. (2004) developed an ELISA-type immunoenzymatic assay for diagnosis of bovine brucellosis using monoclonal antibodies as capture elements and a protein $\mathrm{G}$ conjugate as detector reagent that, on previous studies, showed a high affinity of this protein for the IgG. Tables 1 and 2 show the results of the evaluation of LFIA-PG and LFIA-PA variants against 449 reference bovine serum samples.
Table 1. Results of the evaluation of the LFIA-PG system with bovine reference panel.

\begin{tabular}{lccc}
\hline \multirow{2}{*}{ LFIA-PG } & \multicolumn{3}{c}{ Reference Panel } \\
\cline { 2 - 4 } & $\begin{array}{c}\text { Reactive } \\
\text { Samples }\end{array}$ & $\begin{array}{c}\text { Non-Reactive } \\
\text { Samples }\end{array}$ & Total \\
\hline Positive & 111 & 13 & 124 \\
Negative & 0 & 325 & 325 \\
\hline Total & 111 & 338 & 449 \\
\hline
\end{tabular}

Table 2. Results of the evaluation of the LFIA-PA system with a bovine reference panel.

\begin{tabular}{lccc}
\hline \multirow{2}{*}{ LFIA-PA } & \multicolumn{3}{c}{ Reference Panel } \\
\cline { 2 - 4 } & $\begin{array}{c}\text { Reactive } \\
\text { Samples }\end{array}$ & $\begin{array}{c}\text { Non-Reactive } \\
\text { Samples }\end{array}$ & Total \\
\hline Positive & 106 & 9 & 115 \\
Negative & 5 & 329 & 334 \\
\hline Total & 111 & 338 & 449 \\
\hline
\end{tabular}

Table 3. Results of the performance parameters of the LFIAPG and LFIA-PA systems according the bovine samples studied.

\begin{tabular}{lcc}
\hline Performance Parameters & LFIA-PG & LFIA-PA \\
\hline Diagnostic Sensitivity & $100 \%$ & $95.5 \%$ \\
Diagnostic Specificity & $96.2 \%$ & $97.3 \%$ \\
Efficacy & $97.1 \%$ & $96.89 \%$ \\
Positive Predictive Value & $89.5 \%$ & $92.3 \%$ \\
Negative Predictive Value & $100 \%$ & $98.5 \%$ \\
Kappa & 0.95 & 0.95 \\
\hline
\end{tabular}

Table 4. Concordance results between LFIA-PG and LFIAPA systems.

\begin{tabular}{cccc}
\hline \multirow{2}{*}{ LFIA-PG } & \multicolumn{3}{c}{ LFIA-PA } \\
\cline { 2 - 4 } & Positive & Negative & Total \\
\hline Positive & 117 & 6 & 123 \\
Negative & 6 & 320 & 326 \\
\hline Total & 123 & 326 & 449 \\
\hline
\end{tabular}

kappa: 0.95 .

LFIA-PG was found to be more sensitive than LFIAPA because it identified all the positive samples, while the sensitivity showed by LFIA-PA was $95.5 \%$ (Table 3).

The specificity level was $96.2 \%$ for LFIA-PG and 97.3\% for LFIA-PA, being slightly higher in the LFIAPA variant. Similar results of sensitivity and specificity were obtained by Montasser et al. (2012) when they evaluated an immunochromatographic test on latex particles for diagnosis of brucellosis in cattle, sheep and goats in Egypt.

Elshemey and Abd-Elrahman (2014) also obtained $94.4 \%$ sensitivity and $100 \%$ specificity in the 
evaluation of these parameters in a rapid test for Brucella abortus in bovine sera. Similarly, Abdoel et al. (2008) reported a sensitivity over $95 \%$ in the evaluation of a lateral flow system for the detection of brucellosis in cattle. Díaz et al. (2015) evaluated the LFIA-PA variant functionality with 206 bovine samples and obtained sensitivity and specificity values of $98.3 \%$ and $100 \%$, respectively.

Immunoglobulin binding proteins, such as protein A, $\mathrm{G}$, or recombinant protein A / G, have been used as valuable tools in diagnostic systems for the detection of anti-Brucella antibodies in different animal species (Elshemey and Abd-Elrahman, 2014; Nicola et al., 2014; Shome et al., 2015).

Protein A reacts more specifically with the $\operatorname{IgG} 2$ subclass, whereas protein $\mathrm{G}$ reacts with both subclasses of bovine $\operatorname{IgG}$ ( $\operatorname{IgG} 1$ and $\operatorname{IgG} 2$ ), which allows detecting antibodies at any time of infection (Díaz et al., 2015; Shome et al., 2015). In comparative immunological studies on affinity and specificity of proteins $A$ and $G$, protein $G$ showed a greater affinity for G-type bovine immunoglobulins (Nielsen et al., 2004; Pajuaba et al., 2010; Genç et al., 2012).

The present study showed the greater affinity of protein $\mathrm{G}$ for bovine immunoglobulins compared with protein A, observed in the results of sensitivity and specificity obtained by the LFIA-PG system. Sensitivity and specificity are essential parameters that allow making inferences from the results of an assay (Genç et al., 2011; Ochoa, 2013). Both parameters define the effectiveness of a system since they ensure that the proportion of the infected animals will give positive results to the test; however, the animals still infected give a negative result. We are then in the presence of a false negative result and in a situation in which the proportion of uninfected animals will give negative results.

When uninfected animals give a positive result, we are in the presence of false positive results (Genç et al., 2011). The efficacy in both variants was similar; however, the effect of the false results was different in both variants. With LFIA-PG, there were no falsenegative results, and 13 false positives were identified with an efficacy of $97.1 \%$. With LFIA-PA, 9 false positives and 5 false negatives were identified for an efficacy of $96.89 \%$. This element should also be taking into account to decide the variant to use.. As previously stated, the fact that no false-negative results were identified means that all the positive samples were correctly identified with the LFIA-PG variant, which makes it effective for the detection of antibodies against Brucella spp.

Table 3 shows the results of VPP and VPN. In both tests, high VPP and VPN results were achieved. The analysis of the predictive values showed that the LFIAPG variant showed a VPN of $100 \%$, which made it suitable for the research. It is evident that the tests with a high negative predictive value are preferred for brucellosis screening because their use minimizes the probability for an infected animal to be identified as false negative.

The systems with a high positive predictive value are very useful for disease confirmation because the probability of an uninfected animal being identified as false positive is low (Silva et al., 2006; Al Dahouk et al., 2013).

VPP and VPN are measurable parameters in the performance of the diagnostic methods. They can be modified drastically according to the prevalence of the disease and with some immunological, genetic or biochemical markers studied in a population. The calculation of these predictive values guides the researcher about the possible utility of the diagnostic method towards its use as a screening or confirmation system (Silva et al., 2006).

Table 4 shows the concordance between the two variants. The concordance is a measurable parameter; it is the percentage of coincident results between two tests performed on the same sample (NRGA 586, 1982; Silva et al., 2006). The kappa index is one of the parameters used when it is required an evaluation of two systems against the same reference sample panel (Saegerman et al., 2004). In this study, a kappa index of 0.95 was obtained, resulting in a very good concordance between both variants.

Other authors have also used the concordance as a statistical method for the analysis of their results, and it was the case of Díaz et al. (2015), when they compared LFIA-PA system with the Rose Bengal reference test, which is one of the most used tests in Cuba and worldwide (NRAG 586, 1982), to carry out Brucellosis screening with 206 samples of bovine serum. The value of $k$ they obtained was 0.95 , meaning a very good concordance. Silva et al. (2006) also obtained similar concordance results (98\%) with 1178 bovine samples for a $k$ of 0.98 when they used an ELISA assay based on the inhibition principle, designed for brucellosis serological diagnosis in different animal species.

Although brucellosis is a well-managed disease, it continues posing a threat to the public and veterinary health in both developed and developing countries (Beesley, 1989; Nielsen et al., 2007; Aranís et al., 2008). Reaching an effective diagnosis is one of the premises to achieve good management of the disease (Beesley, 1989; Al Dahouk et al., 2013; Moreno, 2014). Some authors (Saegerman et al., 2004; Silva et al., 2006; Aranís et al., 2008; Genç et al., 2012; Montasser et al., 2012; Nicola et al., 2014; Díaz et al., 2015) suggest to use diagnostic strategies with highly sensitive tests and less specificity for screening, and then use a more specific test to confirm positive animals. 


\section{Conclusions}

The developed LFIA-PG system was capable of detecting antibodies against Brucella spp. Its diagnostic performance showed high values in the analyzed parameters compared with the LFIA-PA system. Performance results together with the ease and speed in the execution of the test make possible its use as a screening method for diagnosis of brucellosis, as well as for this disease surveillance and management in cattle. We recommend following up this study carrying out field evaluations in bovine populations with different epizootiological conditions, as well as in other livestock species of interest.

\section{Conflict of interest}

The Authors declare that there is no conflict of interest.

\section{References}

Abdoel, T., Travassos, I., Cardoso, R. and Smits, H.L. 2008. Simple and rapid field tests for brucellosis in livestock. Vet. Microbiol. 130, 312-319.

Al Dahouk, S., Sprague, L.D. and Neubauer, H. 2013. New developments in the diagnostic procedures for zoonotic brucellosis in humans. Rev. Sci. Tech. Off. Int. Epiz. 32(1), 177-188.

Aranís, C., Oporto, J., Espinoza, M., Riedel, I., Pérez, C. and García, P. 2008. Usefulness of the determination of IgG and IgM antibodies by ELISA and immunocapture in a clinical series of human brucellosis. Rev. Chil. Infect. 25(2), 116-121.

Bamaiyi, P.H. 2016. Prevalence and risk factors of brucelosis in man and domestic animals: A review. Int. J. One Health 2, 29-34.

Beesley, J. 1989. Colloidal gold. A new perspective for cytochemical marking. Royal Microscopical Society Handbook N. 17. Oxford Science Publications. Oxford University Press.

Díaz, D.F., Cruz, Y., Cruz, O., Martín, D., Alfonso, M.J., Ortiz, E., Fragas, A., Montano, L. and Silva, E. 2015. Development and evaluation of the performance of a rapid immunochromatographic test for the diagnosis of brucellosis. Rev. Salud. Anim. 37(2), 105-111.

Dongre, J. and Maheshwari, P. 2013. An immunochromatographic assay for rapid diagnosis of brucella infection in cattle. Int. J. Agric. Sci. Vet. Med. 1(4), 77-80.

Elshemey, T.M. and Abd-Elrahman, A.H. 2014. Evaluation of a rapid Immunochromatografic test for Detection of Brucella abortus Antibodies in Egyptian Cattle Sera and Milk. Alexandria J. Vet. Sci. 40(1), 24-28.

Galińska, E.M. and Zagórski, J. 2013. Brucellosis in 37 humans - etiology, diagnostic, clinical forms. Ann. 38 Agric. Environ. Med. 20(2), 233-238.

Gasque, R. 2008. Brucellosis. In Enciclopedia Bovina, Capitulo 4. Enfermedades de los Bovinos, Eds.,
Universidad Nacional Autónoma de México. Facultad de Medicina Veterinaria y Zootecnia, pp: 102-106.

Genç, O., Bûyûktanir, Ô. and Yurdusev, N. 2011. Development of an individual rapid test based on enzymatic immunofiltration assay for detection of anti-Brucella abortus antibody in bovine sera. J. Vet. Diagn. Invest. 23, 49-56.

Genç, O., Bûyûktanir, Ô. and Yurdusev, N. 2012. Rapid immunofiltration assay based on colloidal goldprotein $\mathrm{G}$ conjugate as an alternative screening test for bovine and ovine brucelosis. Trop. Anim. Health Prod. 44, 213-215.

Geresu, M. and Kassa, G.A. 2016. Review on Diagnostic Methods of Brucellosis. J. Vet. Sci. Technol. 7(3), 1-8.

Hermanson, G. 1996. Bioconjugate Techniques. USA. Edit. Academic Press, pp: 593-604.

Montasser, M., Khoudair, M., Soliman, S. and Eman, A. 2012. Evaluation of Immunochromatographic assay for serodiagnosis of Brucella among cattle, sheep and goats in Egypt. Glob. Vet. 8(5), 511-518.

Moreno, E. 2014. Retrospective and prospective perspectives on zoonotic brucelosis. Front. Microbiol. doi: 10.3389/fmicb.2014.00213.

Nicola, A.M., Arocena, G.M., Cravero, S.L., Trangoni, M.D., Escobar, O.E., Elena, S., Franco, C., Bagnat, E. and Manetti, J.C. 2014. Biotechnological development of test strips for the diagnosis of field brucellosis. SNS. 4, 44-48.

Nielsen, K., Smith, P., Yu, W.L., Nicoletti, P., Elzer, P., Vigliocco, A., Silva, P., Bermudez, R., Renteria, T., Moreno, F., Ruiz, A., Massengill, C., Muenks, Q., Kenny, K., Tollersrud, T., Samartino, L., Conde, S., Draghi de Benitez, G., Gall, D., Perez, B. and Rojas, X. 2004. Enzyme immunoassay for the diagnosis of brucellosis: chimeric protein A Protein $\mathrm{G}$ as a common enzyme labeled detection reagent for sera for different animal species. Vet. Microbiol. 101(2), 123-129.

Nielsen, K., Smith, P., Yu, W.L., Elmgren, C., Nicoletti, P., Perez, B., Bermudez, R. and Renteria, T. 2007. Second generation competitive enzyme immunoassay for detection of bovine antibody to Brucella abortus. Vet. Microbiol. 124, 173-177.

NRAG 586. 1982. Diagnóstico Veterinario. Brucelosis. Métodos de ensayo. Ministerio de la Agricultura, Norma Ramal, Cuba.

Ochoa, R.F. 2013. Immunoenzymatic techniques in the clinical development of vaccines. Section I. Chapter 3. Validation of quantitative and qualitative immunoassays. Finlay Editions; ISBN 978-9597076-50-6.

OIE (World Organization for Animal Health). 2016. Terrestrial Manual: Chapter 2.1.4. Brucellosis (Brucella abortus, B. melitensis and B. suis). 
Infection with B. abortus, B. melitensis and B. sui. pp: 1-44.

Pajuaba, A., Silva, D. and Mineo, J.R. 2010. Evaluation of Indirect Enzyme-Linked Immunosorbent Assays and IgG Avidity Assays Using a Protein APeroxidase Conjugate for Serological Distinction between Brucella abortus S19-Vaccinated and Infected. Cows. Clin. Vaccine Immunol. 17(4), 588-595.

Saegerman, C., De Waele, L., Gilson, D., Godfroid, J., Thiange, P., Michel, P., Limbourg, B., Vo, T.K., Limet, J., Letesson, J.J. and Berkvens, D. 2004. Evaluation of three serum ELISAs using monoclonal antibodies and protein $\mathrm{G}$ as peroxidase conjugate for the diagnosis of bovine brucellosis. Vet. Microbiol. 100, 91-105.

Sbriglio, J.L., Sbriglio, H. and Sainz, S. 2007. Brucellosis. A pathology generally underdiagnosed in Humans and that negatively impacts the livestock production and development of our countries. Rev. Bioanálisis pp: 18-22.

Shome, R., Filia, G., Padmashree, B.S., Krithiga, N., Sahay, S., Triveni, K., Shome, B.R., Mahajan, V., Singh, A. and Rahman, H. 2015. Evaluation of lateral flow assay a field test for investigation of brucellosis outbreak in an organized buffalo farm: A pilot study. Vet. World 8(4), 492-496.

Silva, E., Izquierdo, M., Nibot, C. and Martín, R.Z. 2006. Evaluation of the DAVIH BRU 3 ELISA system in the diagnosis of Brucellosis in different animal species. Rev. Salud. Anim. 28(1), 31-35.

Smits, H.L., Abdoel, T.H., Solera, J., Clavijo, E. and Díaz, R. 2003. Immunochromatographic Brucellaspecific immunoglobulin $M$ and Glateral flow assays for rapid serodiagnosis of human brucelosis. Clin. Diagnost. Lab. Immunol. 10(6), 1141-1146. 